\title{
Distal arthrogryposis: a new type with distinct facial appearance and absent teeth
}

\author{
Rodney K Beals, Stephen LaFranchi
}

EDITOR - The distal arthrogryposes are a group of inherited disorders with congenital contractures of the distal extremities. A father and daughter with similar distal extremity contractures, distinct facial features, depressed coronal sutures, and congenitally absent teeth characterise a new type of distal arthrogryposis.

\section{Case report}

An 11 year old girl was seen for evaluation of finger contractures. She had been noted at birth to have finger contractures and a "puffy face" (fig 1). Her birth weight was $4077 \mathrm{~g}$ and her length was $51 \mathrm{~cm}$. At 11 months of age she had "trigger finger" releases of her fifth digits with some improvement. She was diagnosed at the age of nine with attention deficit disorder and treated with Ritalin. At the age of 10 she was treated by release of contracture and tendon balancing procedure of the right little finger. The left little finger was treated with a splint. There was no clinical evidence of neurological or muscle disease. She was at the 50th centile in height until 9 years when the rate of growth decreased.

Examination at 11 years showed a head circumference of $51 \mathrm{~cm}(50 \%)$, small and horizontal palpebral fissures, epicanthic folds, mild micrognathia, and palpable depression of the coronal transverse suture. There was broadening of the nose adjacent to the epicanthic fold, the columella was under the tip of the nose, and the upper lip was in the shape of a cupid's bow (fig 1). Eight permanent bicuspid teeth and the upper left lateral incisor were congenitally absent (fig 2). Her hands showed prominent knuckle pads, symmetrical mild contractures of the proximal interphalangeal joints of the index, middle, and ring fingers and $45^{\circ}$ contracture of the proximal interphalangeal joint of the little fingers of both hands. The thumbs were adducted and flexed. A transverse palmar crease was present and the flexion creases in the fingers were not well developed (fig 3). The elbows and wrists showed mild lack of extension. Pronation and supination were normal. The range of motion of the shoulders and hips was normal. There was $10^{\circ}$ contracture of the knees. The feet showed mild toe stiffness without deformity. Vision, hearing, speech, intelligence, motor development, and chromosome studies were normal. The knee contractures and finger contractures were treated with night splints with no improvement.

At the age of 12, her height was $142 \mathrm{~cm}$ and her weight was $31 \mathrm{~kg}$. Because of a progressive
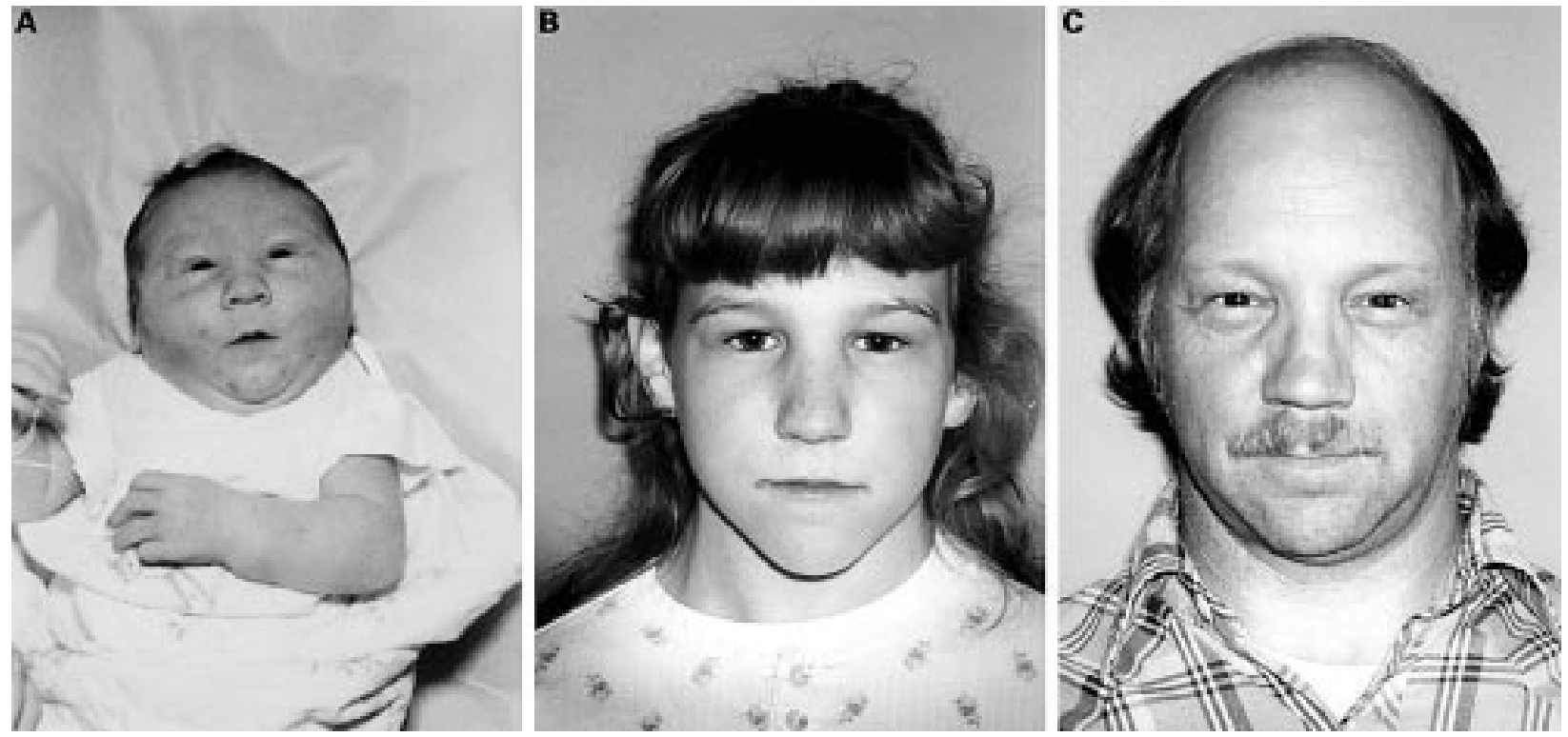

Figure 1 AP photographs of the proband at birth (A), aged 11 (B), and of her father (C) showing small, horizontal palpebral fissures, broad base of the nose, and cupid's bow configuration of the upper lip. Depression of the coronal fissure is palpable but not seen in the photograph. 
drop off in attained height, she was evaluated by insulin and arginine stimulation tests which showed growth hormone deficiency. She

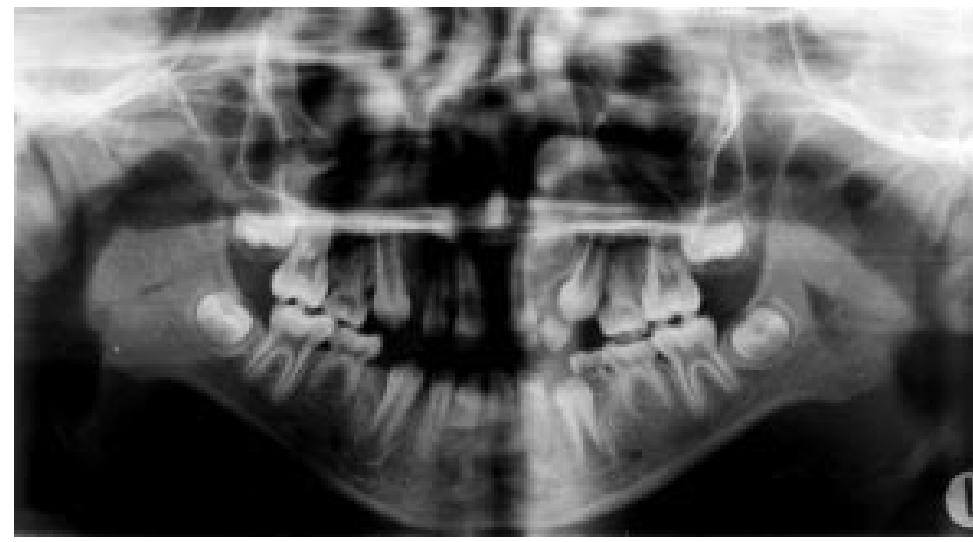

Figure 2 AP radiograph of the jaw of the proband shows congenital absence of bicuspid teeth.
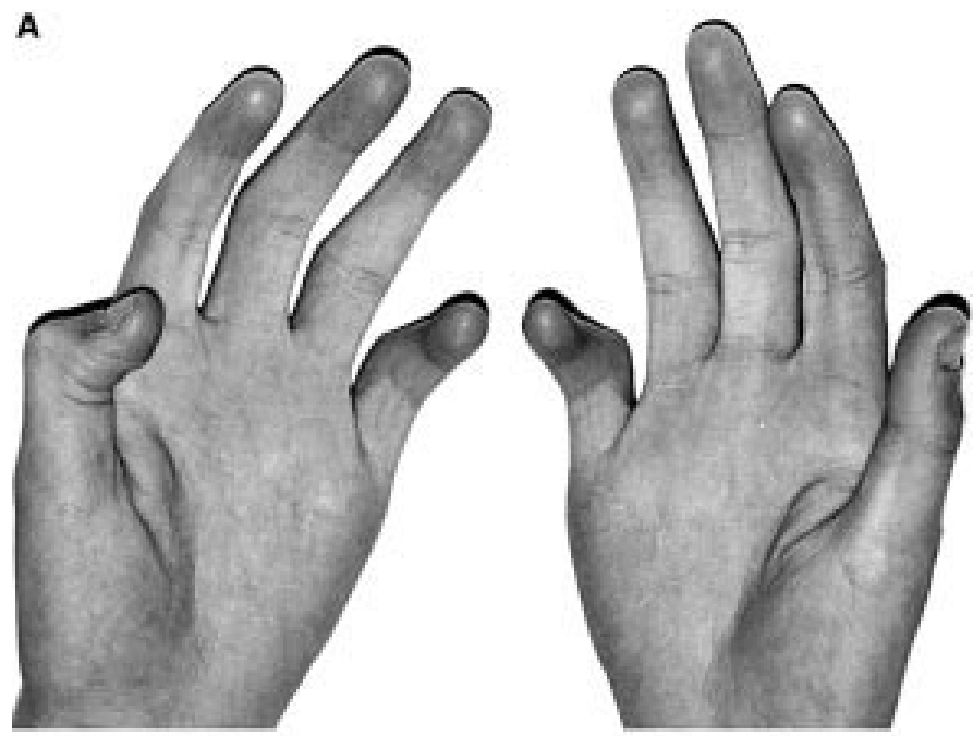

B
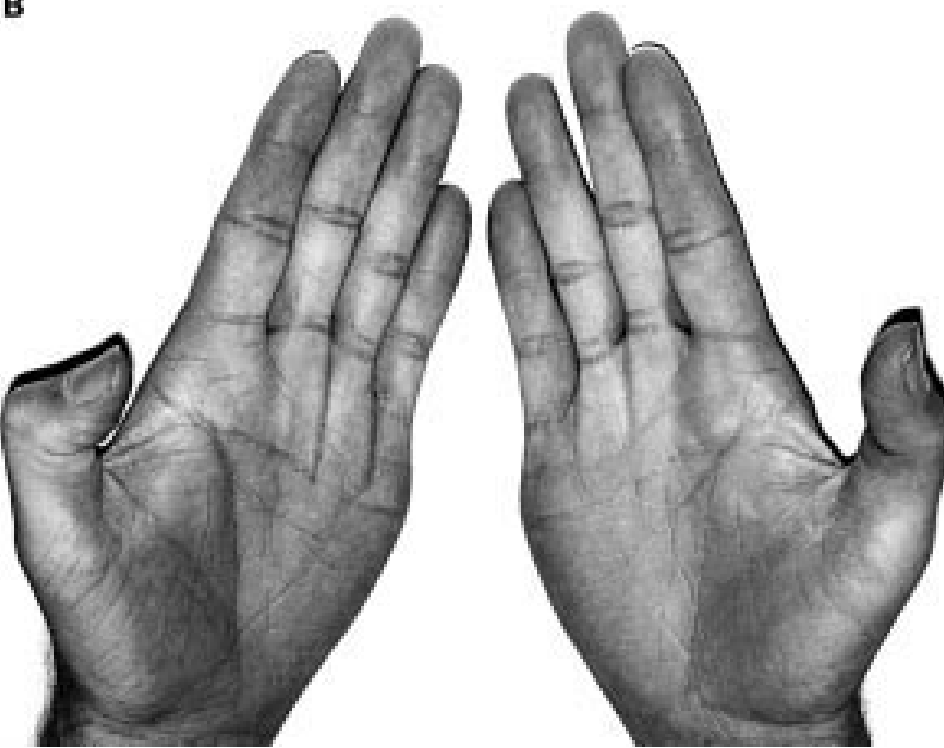

Figure 3 AP photograph of the hands of the proband aged $11(A)$ and of her father $(B)$ show finger contractures, adducted and flexed thumbs, transverse palmar crease, and underdevelopment of the flexion creases of the finger joints. was treated with human growth hormone and has gone from the 29 th centile in height at the age of 12 to the 50 th centile at skeletal maturity.

At the age of 14 , she was noted to a have a $10^{\circ}$ flexion contracture of the left elbow and knee contractures of $10^{\circ}$ and $15^{\circ}$. The knee contractures were treated with casts with minimal improvement. At the age of 15, the passive range of motion of the proximal interphalangeal and distal interphalangeal joints of the ring and little fingers were $35^{\circ}$ of flexion to $50^{\circ}$ of flexion. The thumbs had full range of passive motion. At the age of 16 , a progressive bunion deformity of the right foot was treated by a metatarsal osteotomy and medial capsular reefing.

The family includes a similarly affected father and unaffected mother and sister. Her father had a height of $1.72 \mathrm{~m}$ and facial features similar to those of his daughter (fig 1). He had congenital absence of eight teeth and now wears dentures. His hands showed mild contractures of the proximal interphalangeal joints of the fingers and prominent knuckle pads. Flexion of the distal interphalangeal joints was limited to $45^{\circ}$ and the flexion creases of the distal interphalangeal joints were underdeveloped (fig 3). His thumbs were adducted and flexed but there were no fixed contractures. The proximal interphalangeal joints of the toes and the interphalangeal joint of the big toe were stiff. There were no knee contractures. His right elbow lacked $15^{\circ}$ of extension and the forearm lacked $10^{\circ}$ of pronation. He has been diagnosed as having an attention deficit disorder, Ménière's disease, and otosclerosis.

\section{Discussion}

Arthrogryposis is defined as the presence of non-progressive congenital contractures of two or more body areas. Distal arthrogryposis primarily involves the distal extremities and was classified by Hall et al in 1982. The Hall classification distinguished six types of peripheral contractures based on the presence or absence of associated anomalies in addition to the pattern of peripheral contractures. It did not include all syndromes known to have peripheral contractures and included some that were not known to be inherited. ${ }^{1}$ The Hall classification has been modified by Bamshad et $a l^{2}$ who defined distal arthrogryposis as "an inherited primary limb malformation disorder characterized by congenital contractures of two or more different body areas and without primary neurologic and/or muscle disease that affects limb function". Deformities of the upper extremities include congenital ulnar deviation, camptodactyly (or pseudocamptodactyly), hypoplastic and/or absent flexion creases, and overriding fingers. Deformities in the lower limbs include talipes equinovarus, calcaneovalgus, vertical talus, and metatarsus varus but are not limited to these deformities. Nine malformation syndromes meeting these criteria have been described that have in common a consistent pattern of distal joint 
contracture, minimal proximal joint involvement, and autosomal dominant inheritance. ${ }^{1-11}$ While the classification is clinically useful, some of these conditions have been shown to have genetic heterogeneity. ${ }^{12}$

The family described here is different from other patients reported with distal arthrogryposis. This family has congenital contractures of the fingers and deformity of the thumb. Distinctive facial features were present at birth and include small and horizontal palpebral fissures, broadening of the nose, a cupid's bow configuration of the upper lip, depression of the coronal suture, and congenital absence of bicuspid teeth. There are mild contractures at the elbows and knees and limited motion of the toes. Treatment of the contractures of the knee and fingers in this patient have had limited success. These features are present in a father and daughter. It is not clear that growth hormone deficiency, present in the index patient, is a part of the syndrome. The report of other similarly affected families will be necessary to clarify the phenotype and inheritance of this syndrome.
1 Hall JG, Reed SD, Greene G. The distal arthrogryposes: delineation of new entities - review and nosologic delineation of new entities - review and
discussion. Am f Med Genet 1982;11:185-239.

2 Bamshad M, Jorde LB, Carey JC. A revised and extended classification of the distal arthrogryposes. Am $\mathcal{F}$ Med Genet 1996;65:277-81

3 Beals RK, Hecht F. Congenital contractural arachnodactyly. A heritable disorder of connective tissue. F Bone foint Surg Am 1971;53:987-93.

4 Goldberg MJ. The dysmorphic child. New York: Raven Press, 1987:22-36.

5 Hecht F, Beals RK. Inability to open the mouth fully: an autosomal dominant phenotype with facultative campylodactyly and short stature. Preliminary note. Birth Defects 1969;5:96-8.

6 McKeown CM, Harris R. Autosomal dominant multiple pterygium syndrome. F Med Genet 1988;25:96-103.

7 Rinsky LA, Bleck EE. Freeman-Sheldon ("whistling face") syndrome. F Bone foint Surg Am 1976;58:148-50.

8 Robinson M, Johnson GF. The Gordon syndrome: autosomal dominant cleft palate, camptodactyly, and clubfeet. Am f Med Genet 1981;9:139-46.

9 Sallis JG, Beighton, P. Dominantly inherited digito-talar Sallis JG, Beighton, P. Dominantly inherited digito-
dysmorphism. F Bone foint Surg Br 1972;54:509-15.

10 Schrander-Stumpel CT, Howeler CJ, Reekers AD, DeSmet NM, Hall JG, Fryns JP. Arthrogryposis, ophthalmoplegia, and retinopathy: confirmation of a new type of arthrogryposis. F Med Genet 1993;30:78-80.

11 Stewart JM, Bergstrom L. Familial hand abnormalities and sensori-neural deafness: a new syndrome. $f$ Pediatr 1971;78:102-10

12 Bamshad M, Watkins WS, Zenger RK, Bohnsack JF, Carey JC, Otterud B, Krakowiak PA, Robertson M, Jorde LB. A gene for distal arthrogryposis type I maps to the gene for distal arthrogryposis type I maps to the
pericentromeric region of chromosome 9. Am fHum Genet pericentromeric 